\title{
Characterization of seed germination and seedling survival during the initial wet-dry periods following planting
}

\author{
GARY W. FRASIER
}

\begin{abstract}
Combined greenhouse, laboratory, and field studies were conducted to develop techniques which could be used to characterize seed germination and seedling survival of a plant species when subjected to various wet-dry watering sequences following seeding. A procedure was developed to utilize daily seedling count data to estimate the minimum number of seeds which germinate under specific wet-dry watering sequences. These seed germination percentages are used to adjust laboratory/greenhouse results to more accurately predict field results. Results showed no consistent relationships or patterns between germination percentages derived from filter paper experiments and percentages obtained from the seedling count procedure. The germination percentages, determined from seedling emergence data, were used to normalize seedling survival numbers for 3 wet-dry watering sequences determined in greenhouse experiments. With the adjustment for actual seed germination rates occurring in the greenhouse and field, the number of seedlings surviving the wet-dry watering sequences in the greenhouse could be used to estimate the number of seedling surviving the same watering sequences in the field.
\end{abstract}

Key Words: plant establishment, drought tolerance, warm-season grasses

Field evaluation of range plant establishment has, by necessity, been an arduous, high-risk endeavor. Environmental stresses of flucutating temperatures, variable precipitation patterns, poor seedbed preparation, and plant competition make it difficult to develop an understanding of the interactions of the various components involved in plant establishment (Asay and Johnson 1987). Many years of data collection are frequently required to achieve significant results. Cox and Jordan (1983) estimated that successful seedings in Southern Arizona would occur only 1 year in 10 because of unfavorable precipitation totals and/or distributions at critical time periods during the seedling establishment process.

To reduce the time necessary to achieve consistent results, laboratory/greenhouse studies are used to control or limit the number of environmental variables (Sosebee and Herbel 1969). Unfortunately, the translation or extension of the laboratory results to field conditions is not straightforward and can lead to erroneous conclusions. Asay and Johnson (1983) reported poor correlation between laboratory determinations of crested wheat [Agropyron cristatum (L.) Gaertn. and $A$. desertorum (Fisch. ex Link) Schult.] seedling emergence under drought stress and seedling recovery after drought to seedling establishment in the field.

If laboratory/greenhouse studies are to be used to predict what might occur under field conditions, plant responses to critical environmental components such as water and temperature must be properly characterized, both in the laboratory and the field. A common normalizing practice used in evaluating differences in plant establishment characteristics among species, is to use standard laboratory germination tests of total pure live seed (pls) for

\footnotetext{
Author is research hydraulic center engineer, USDA-ARS, Aridland Watershed Management Research Unit, 2000 East Allen Road, Tucson, Arizona 85719.

The author wishes to thank Mr. John R. Griggs, physical science technician, for his diligence and assistance in collecting the data.

Manuscript accepted 13 December 1988.
}

normalizing seedling count data (Association of Official Seed Analysis 1970). In most instances, laboratory germination tests do not represent the seedbed environmental conditions which exist in the field or greenhouse soils (Collis-George and Hector 1966). New techniques must be developed to normalize the results of laboratory/greenhouse studies for translation to the field.

This paper presents an approach for estimating seed germination percentages that are representative of field conditions during the first wet-dry periods following planting. These seed germination percentages are used to adjust laboratory/greenhouse results of plant establishment characteristics to more accurately predict field results.

\section{Model Hypothesis}

Frasier (1986) presented a conceptual model which described a series of pathways or transition sequences which a seed or seedling may follow during the initial wet-dry sequence following planting. The model provides a means of comparing seedling establishment characteristics as related to water availability but does not allow for any quantitative estimates of plant survival.

Two key time intervals during the plant establishment process are the seed germination and initial seedling survival periods. During these periods, soil moisture must be available in sufficient quantities and duration (wet period) to germinate the seed and develop a seedling capable of surviving in less favorable conditions (dry periods). If the wet period is short, the seeds may not germinate and will survive the wet-dry period as viable seeds. With an adequate length wet period and a short dry period, most seeds will germinate and produce a seedling. As the length of the dry period is extended, the number of germinated seeds producing surviving seedlings is reduced.

Frasier et al. (1985) described a function:

$$
\mathrm{N}(\mathrm{t}), \mathrm{t}=0,1,2, \ldots, 14 \text {. }
$$

The term $N(t)$ signifies the number of live seedlings observed on day ( $t$ ) from (M) seeds planted and subjected to a wet period of length $L_{1}$, followed by a dry period of length $L_{0}$. Typical emerged seedling counts of the process $N(t)$ is shown (Fig. 1) for a specified wet-dry sequence of $t_{w}$ wet days $\left(L_{1}\right)$ followed by a dry period of $t_{a}-t_{w}$ days $\left(L_{0}\right)$. From this information, the following discrete random variables can be identified:

$$
\begin{aligned}
& N_{\max }= \text { the maximum number of emerged seedlings during or foll- } \\
& \text { owing the wet period } L_{1}, \\
& t_{\max }=\text { the number of days from planting till } N_{\max } \text { was observed, } \\
& \text { and, } \\
& \mathbf{N}_{\min }=\text { the minimum number of seedlings after } t_{\max } .
\end{aligned}
$$

The number of seeds $(V)$ which survive the dry period $\left(L_{0}\right)$ can be determined by having a second wet period of sufficient length, $\left(t_{n}-t_{d}\right)$, to germinate any seeds which were still viable. If $N\left(t_{n}\right)$ is the number of seedlings at the end of the second wet period in a wet-dry-wet watering sequence, then the number of seeds surviving a specific wet-dry sequence (V) can be estimated as follows:

$$
\mathrm{V}=\mathbf{N}\left(\mathrm{t}_{\mathrm{n}}\right)-\mathbf{N}_{\min }
$$

The function $G(t)$, Figure 1 , is the accumulated minimum number 


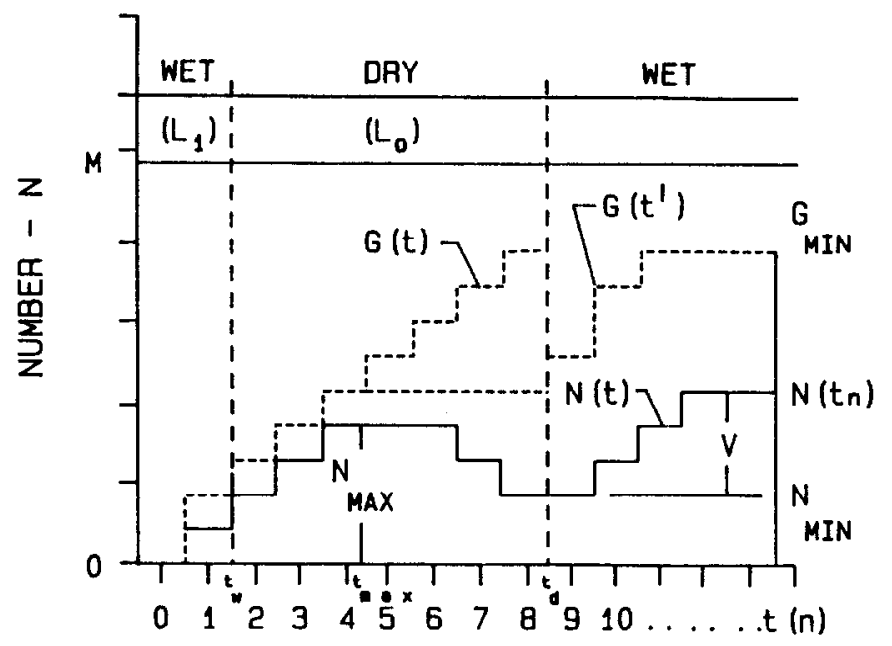

DAY OF STUDY - $(t)$

Fig. 1. Definition sketch of seed germination and seedling emergence response to the first wet-dry watering sequence following planting.

of germinated seeds at time (t) with no dry period $\left(G\left(t^{\prime}\right)\right.$ is the minimum number of germinated seeds with a dry period. Assuming that in both cases all germinated seeds produce a seedling, then the minimum number of germinated seeds is:

$$
\mathrm{G}_{\min }=\mathrm{N}_{\max }+\mathrm{V}
$$

Combining equations (2) and (3) yields,

$$
G_{\min }=N_{\max }+N\left(t_{n}\right)-N_{\min }
$$

The necessary data for equation (4) can be estimated by observing the maximum number of seedlings which result from the initial wet period, the number of seedlings surviving the dry period, and the total number of seedlings at the end of a second wet period, which germinates all remaining viable seeds. Dividing the seedling counts by the number of seeds planted, $(M)$, provides a seed germination percentage derived under the specific wet-dry water conditions. If the wet-dry conditions that might occur in the field following planting can be simulated in the laboratory or greenhouse, this technique can be used to estimate the number of seeds which can potentially produce a plant.

\section{Materials and Methods}

\section{Field Experiments}

Field experiments were conducted on the Walnut Gulch Experimental Watershed near Tombstone, Arizona. The soil was a Sonoita fine-loamy mixed thermic, Typic Haplargid. The area was cleared of vegetation, smoothed with a road grader and loosened to a depth of $120 \mathrm{~mm}$ with a rototiller. One hundred and twenty, 305 by $305 \mathrm{~mm}$ plots were grouped $100 \mathrm{~mm}$ apart in 24 rows of 5 plots each. Rows were spaced $1 \mathrm{~m}$ apart. A wooden border, $50 \mathrm{~mm}$ high, was placed around each plot. Plant species used in the experiments were: sideoats grama (Bouteloua curtipendula (Michx.) Torr., 'Premier'), Lehmann lovegrass (Erogrostis lehmanniana Nees, 'A$68^{\circ}$ ), Boer lovegrass ( $E$. curvula var conferta (Schrad.) Nees, 'Catalina'), Cochise lovegrass (E. lehmanniana Nees $\times E$. trichophora Coss and Dur.), and blue panicgrass (Panicum antidotal Retz, 'SDT'). Species were randomly assigned to 1 of the 5 plots in each row.

All plots were wetted with $3 \mathrm{~mm}$ of water and the surface smoothed. An impression plate was used to form 100 small depres- sions, $6 \mathrm{~mm}$ deep and $25 \mathrm{~mm}$ apart on a $10 \times 10$ grid, on each plot surface. Each plot was seeded with 100 seeds, 1 seed in each depression, with a vacuum seed planter and covered with a 2- to 3-mm layer of soil as described by Frasier (1985).

The watering sequences consisted of: (1) an initial wet period, (2) a dry period, and (3) a final wet period. Two separate experiments of 120 plots each were conducted consecutively. In Experiment 1, the wet-dry-wet watering sequences were: $2-5-7,3-5-6$, and 5-5-4 days, respectively. In Experiment 2 the wet-dry-wet sequences were: $2-7-7,3-7-6$, and 5-7-4 days, respectively. A daily wet (14-0 or 16-0) water sequence was included in Experiments No. 1 and No. 2 respectively. Each row was randomly assigned a watering sequence. A single fan-shaped deflector nozzle on a reciprocating spray bar sprayed water downward onto a single row from a height of 250 $\mathrm{mm}$. The nozzle applied $0.8 \mathrm{~mm}$ of water per pass. All plots in a row received the same quantity of water. Ten to $12 \mathrm{~mm}$ of water were applied immediately following seeding, which wetted the soil to a depth of approximately $100 \mathrm{~mm}$. On each subsequent day at 0700 hours, the plots (rows) in a wet sequence were sprinkled with water at a rate equal to the evaporation loss that had occurred during the previous 24 hours from an adjacent Standard Class A evaporation pan. On the first day following the dry period the plots received $12-14 \mathrm{~mm}$ of water.

A grid template was used to pinpoint the location of the planted seeds (Frasier 1985). Seedlings were counted daily for the 14-16 day study periods at 0600 hours. Any visible sign of a plant was recorded as a seedling. The experimental design for each experiment was a randomized block with 6 block replications, 4 watering sequences, and 5 species.

\section{Greenhouse Experiment}

The greenhouse experiment was conducted using the procedure reported by Frasier et al. (1984). The grass species and watering sequences were the same as used in the first field experiment. Tapered plastic cones, $63.5-\mathrm{mm}$ in diameter by $240-\mathrm{mm}$ long were filled with $660 \mathrm{~g}$ of sand. Ten seeds were placed on the dry surface of each cone and covered with a 2- to 3-mm layer of dry sand. Ten cones were prepared for each grass species per watering sequence.

Water was sprinkled onto the cones with an overhead reciprocating spray system. All cones were initially wetted to approximate field capacity with $66 \mathrm{~g}$ of water ( $10 \%$ moisture by weight). Daily, at $\mathbf{0 7 0 0}$ hours the cones were sprinkled with sufficient water to bring the average moisture content of the sand to the original field capacity weight. Cones in a dry-day portion of the watering sequences were covered during sprinkling with a removable galvanized sheetmetal roof.

Live seedlings in each cone were counted and recorded daily for 14 days at 0600 hours. The total seedling count of the cones of the same species in each watering sequence was summed as a single count. The experiment was repeated 3 times.

Estimates of the seed germination percentages at 10 days of each species were determined by placing 25 seeds between 2 disks of Whatman No. 3 filter paper wetted with distilled water in covered petri dishes in a $26.7^{\circ} \mathrm{C}$ incubator. The filter paper germination tests were conducted simultaneously with the greenhouse experiments.

\section{Data Analyses}

The studies were conducted to determine if techniques could be developed to utilize seed germination, seedling survival characteristics from greenhouse studies to estimate seedling survival numbers in field studies. Data analyses consisted of tabulating the daily seedling counts and selecting the appropriate mean values of maximum, minimum, and final seedling counts for computation of the percentages of germinated seeds and surviving seedlings. Since the object of the study was to develop a model concept for translating 


\section{Results and Discussion}
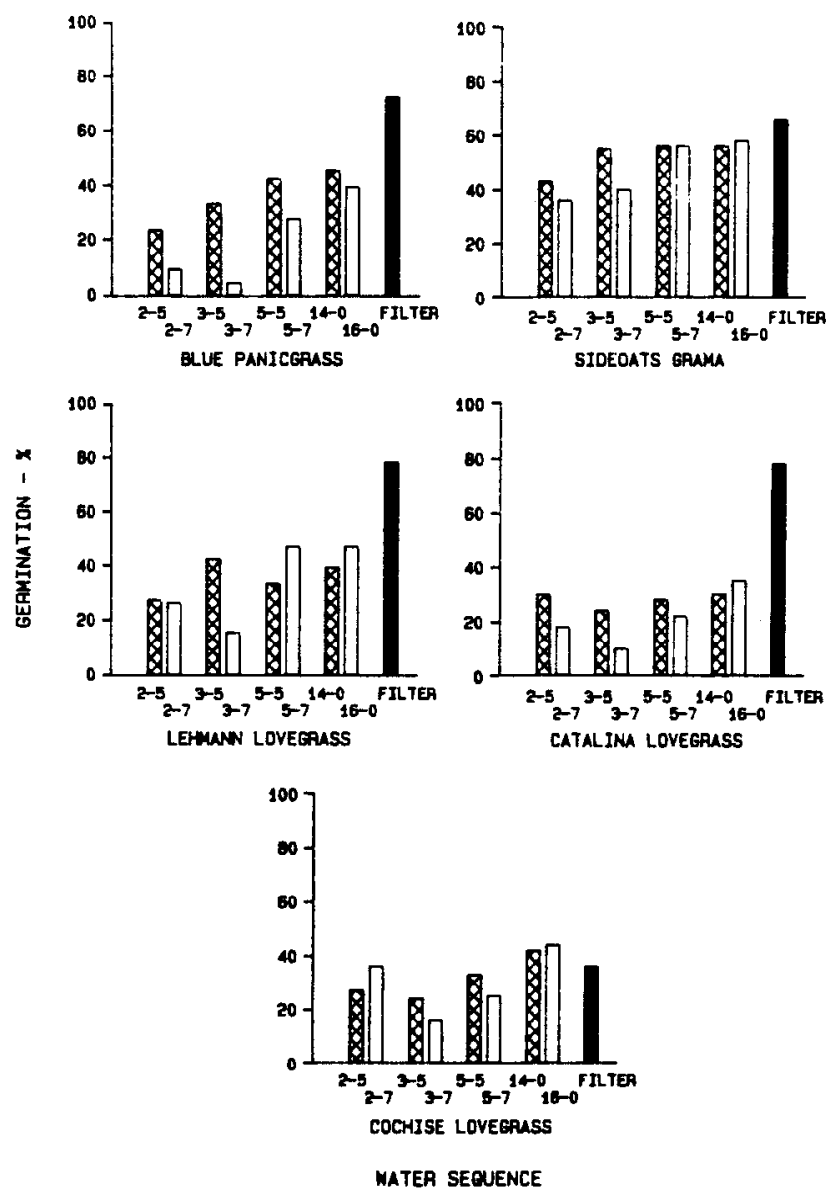

Fig. 2. Germination percentages of 5 grass species determined from filter paper tests and field seedling count data of 8 wet-dry watering sequences.

greenhouse seedling survival data to field conditions, no attempt was made to evaluate differences among species or watering sequences.

\section{Seed Germination}

The minimum total number of seeds which germinated under specific wet-dry watering sequences was evaluated with data from the field experiments. These seedling count germination percentages were compared to the laboratory determined filter paper germination percentages. Daily means of seedling counts in the field experiments were computed for each species and watering sequence combination. The minimum number of seeds which germinated for each combination was computed using equation (4) and converted to a germination percentage (seedling count germination) of the number of seeds planted. With the exception of Cochise lovegrass, the filter paper germination indicated a higher percentage of germinating seeds than was determined in the soil (Fig. 2). The data indicated that, with the species used, the seedling counts from the 14 or 16 day wet watering sequence may be suitable as a first estimate of the number of seeds which will germinate with wet periods of 5 days in length. The 14-day seedling count germination values overestimated actual germination values with shorter wet periods and when the dry period was 7 days in length but provided a closer estimate than when using filter paper values.

\section{Seedling Survival Prediction}

A major objective of the studies was to develop techniques for estimating seedling survival values under field conditions from controlled greenhouse experiments. Comparison of seedling survival data for watering sequences of 2-5, 3-5, and 5-5 wet-dry days shows no consistant relationship in actual seedling counts between the field and greenhouse experiments (Fig. 3).

The greenhouse seedling survival data were then normalized using the filter paper germination percentages and the germination percentages determined from the seedling count of each watering sequence (Equation 4). The data indicated a linear relation of seedling survival to the length of the wet period. The normalized seedling survival data were fit by regression techniques to the equation:

$$
y=A+B x
$$

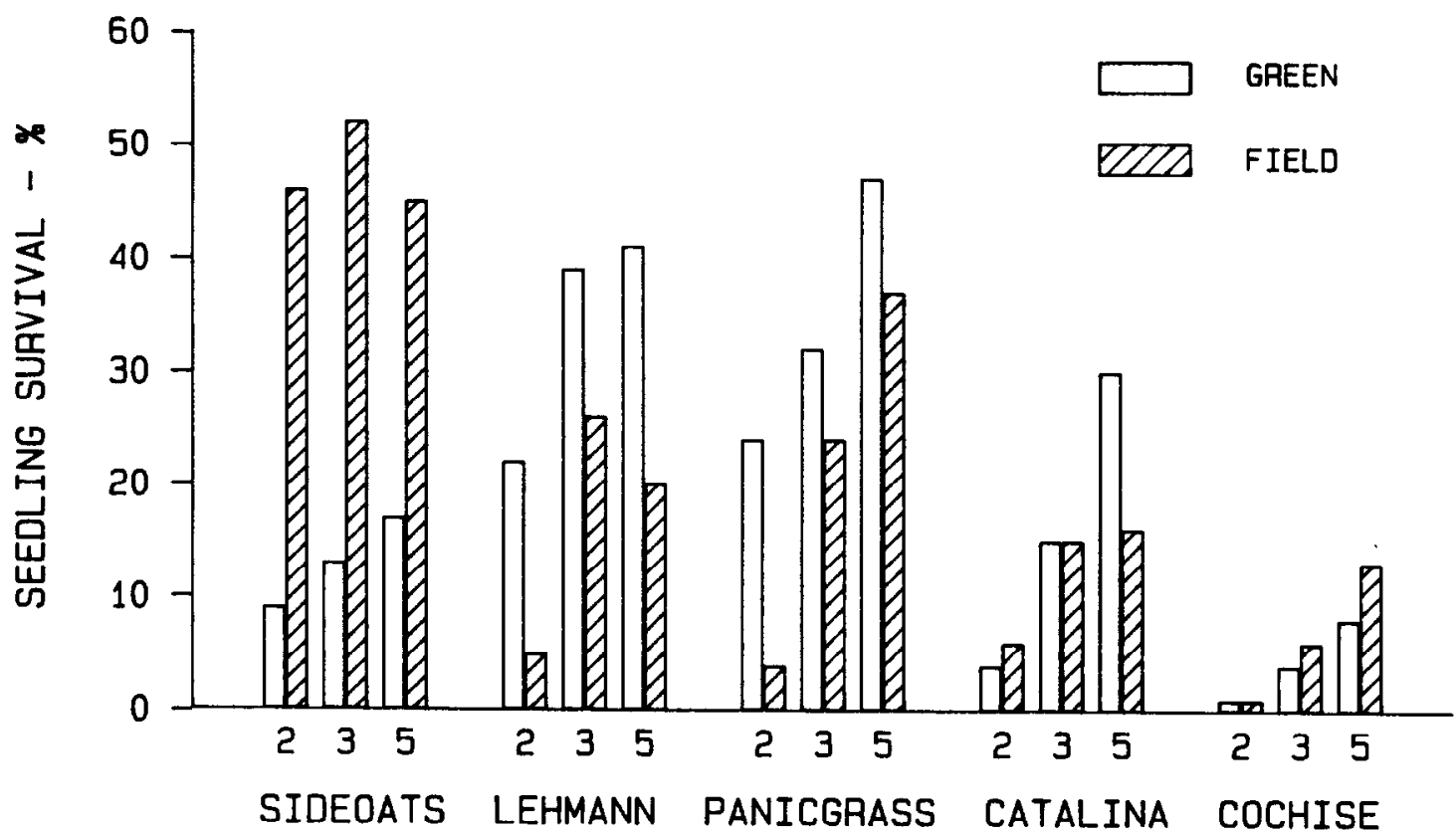

Fig. 3. Seedling survival of 5 grass species in greenhouse and field experiments for 2, 3, and 5 wet days followed by 5 dry days. 


$$
\begin{aligned}
& y=\text { seedling count } \\
& x=\text { number of wet days. }
\end{aligned}
$$

The seedling survival numbers adjusted to filter paper germination were lower than the seedling survival numbers adjusted to seedling count germination percentages (Fig. 4). These regression equations were used to estimate the number of seedlings which might survive the same watering sequences in the field. To allow for different
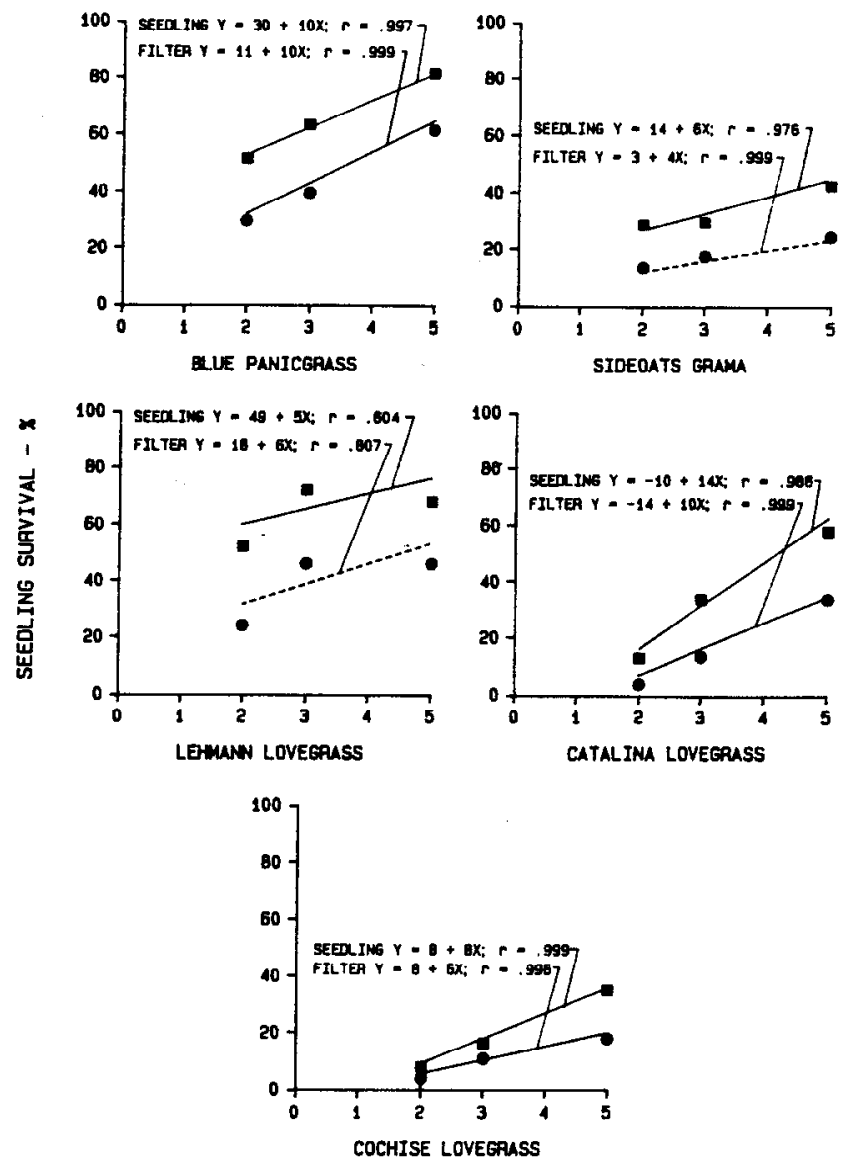

WATER SEQUENCE - WET DAYS

Fig. 4. Seedling survival of 5 grass species in a greenhouse, corrected to filter paper and seedling count (pls) germination percentages for 2,3 , and 5 wet days followed by dry days.

germination rates in the field compared to filter paper and greenhouse conditions, the greenhouse seedling counts were divided by the everyday wet (field, 14-0) germination rates to obtain the projected field seedling counts.

With the exception of sideoats grama, the filter paper (pls) equations overestimated the number of surviving seeds in the field (Fig. 5). A better estimate of the field results was obtained using the greenhouse seedling count germination data adjusted by the germination rate in the field of the everyday wet (14-0) watering sequence. This approach still overestimated actual field seedling survival values but to a lesser amount than the filter paper estimations. With sideoats grama, the greenhouse data, in all cases, underestimated the field seedling survival numbers.

The differences in seedling counts between the greenhouse and. field are attributed to differences in waterholding capacity of the silica sand used as the growing media in the greenhouse and the soil of the field plots. This effect is believed to be the reason for the differences in the computed seedling count germination rates between the greenhouse and field (Fig. 6).
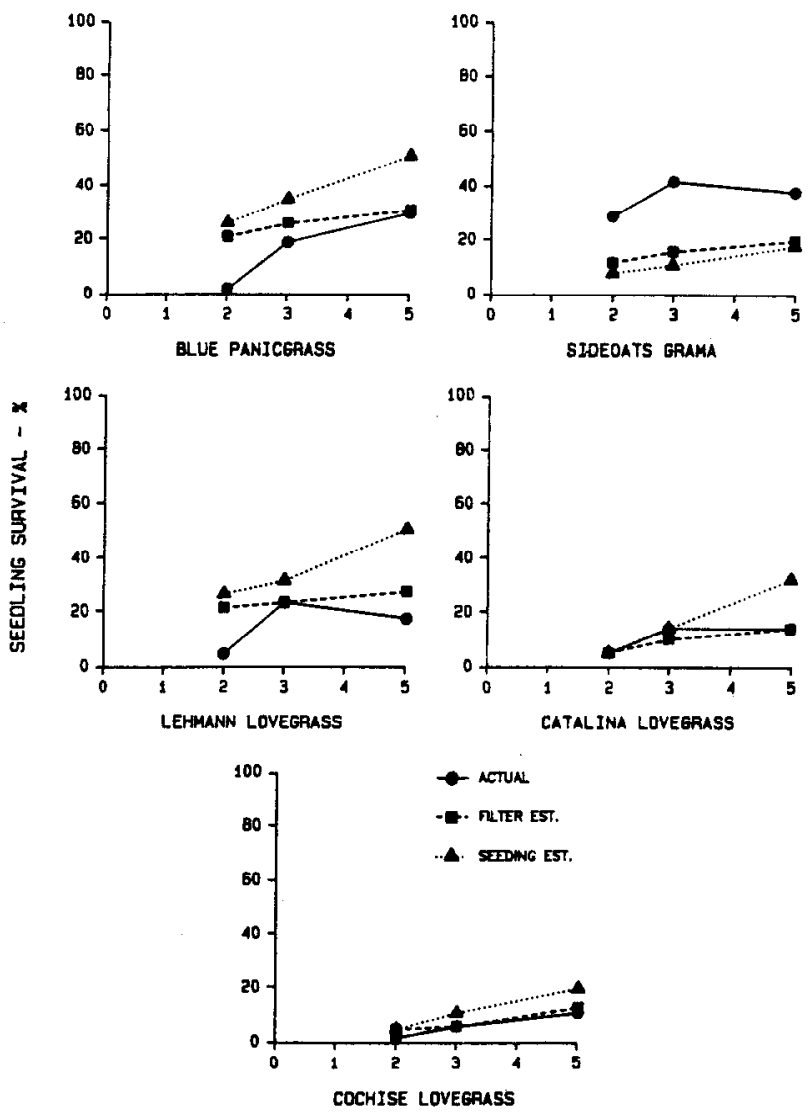

MATER SEQUENCE - MET DAYS

Fig. 5. Actual seedling survival in field plots and estimated seedling survival based on greenhouse results of 5 grass species for 2,3 , and 5 wet days followed by 5 dry days. Greenhouse data normalized by the field 14-0 water sequence germination rates.

If the field germination rates for each watering sequence are used, as opposed to the everyday wet (14-0) sequence, then with the exception of sideoats grama, there is good agreement in the seedling survival counts in the greenhouse and the field experiments (Fig. 7). It is hypothesized that there would have been closer agreement between the greenhouse and the field if the field site soil had been used in the greenhouse studies.

These studies indicate that reasonable estimates of the numbers of surviving seedlings in the field can be obtained from greenhouse experiments by making adjustments for seed germination rates that occur in both the greenhouse and in the field. The best estimates were obtained using the germination rates determined for the specific wet-dry watering sequences. These germination rates may not be readily available or easy to obtain in the field. An alternative is to use the percentage of seedling emergence from small field plot experiments with an everyday wet for 10 to 14 day duration. These seedling counts can be used as an estimator of the minimum number of seeds that will germinate in the field.

\section{Summary and Conclusions}

Laboratory and greenhouse studies were conducted to develop techniques which could be used to characterize seed germination and seedling survival of a plant species when subjected to various wet-dry watering sequences following planting. A model developed by Frasier et al. (1985) was used to describe the number of seedlings observed in an a rea on a given day and subjected to a wet 

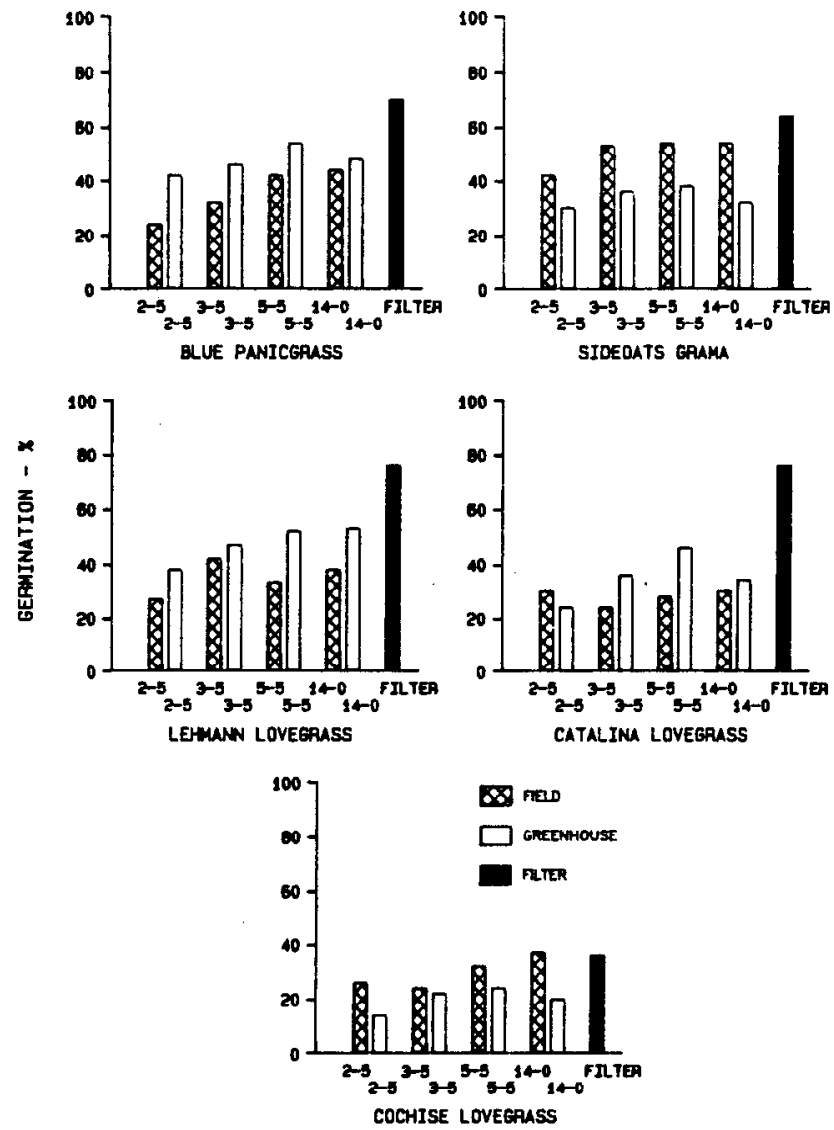

MATER SEQUENCE

Fig. 6. Comparison of greenhouse and field seedling count (pls) germination percentages of 5 grass species for 4 wet-dry day watering sequences.

period of length $L_{1}$, and followed by a dry period of length $L_{0}$. With the model as a guide, techniques were developed to utilize daily seedling count data to estimate the minimum number of seeds which germinate under specific wet-dry watering sequences. The results showed that the number of seeds which germinate under a wet-dry watering sequence and produce a seedling were usually less than indicated by filter paper germination tests. The relative lengths of the wet-dry periods also affected the number of seeds which would germinate.

With adjustments for seed germination rates representative of the watering sequences and seedbed conditions, it was possible to estimate from greenhouse data the number of seedlings which would survive a specific wet-dry watering sequence in the field. This technique makes it possible to conduct relatively simple experiments in a greenhouse or on small field plots and obtain indications of the percentages of seeds which might germinate and producing seedlings for a given wet-dry sequence under field conditions.

\section{Literature Cited}

Asay, K.H., and D.A. Johnson. 1983. Genetic variability for characters affecting stand establishment in crested wheatgrass. J. Range Manage. 36:703-706.
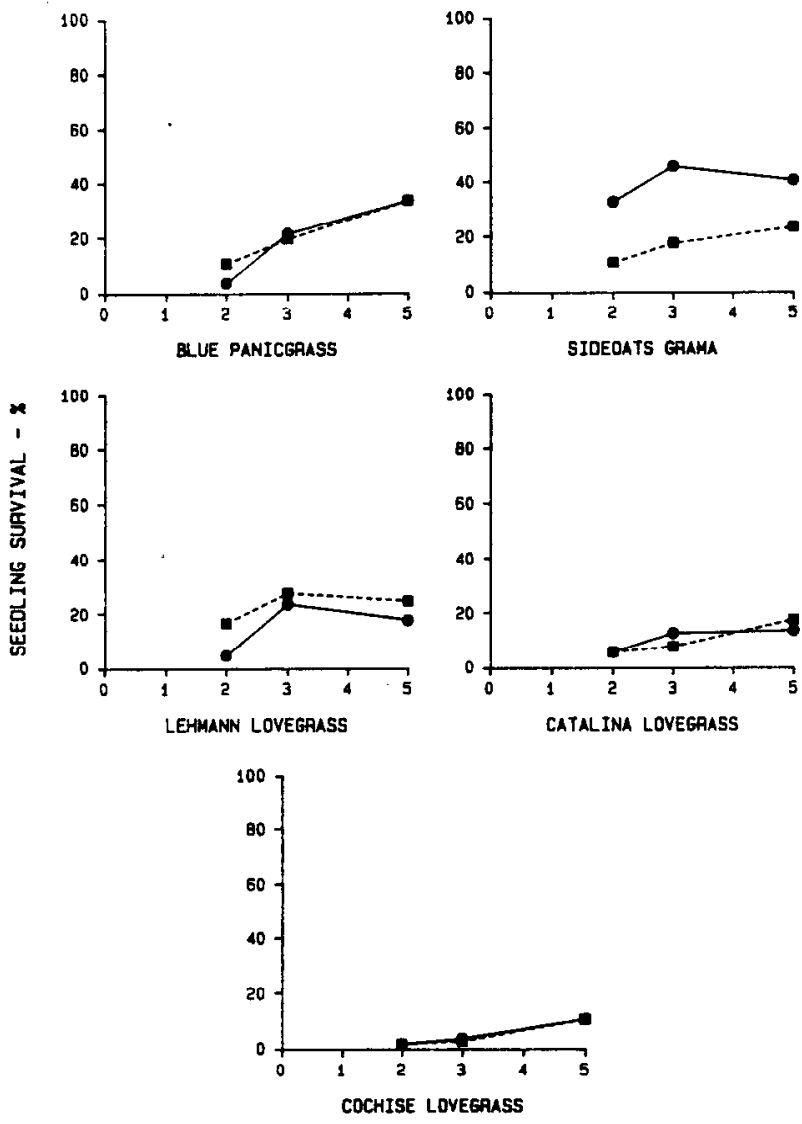

MATER SEQUENCE - MET DAYS

Fig. 7. Actual seedling survival in field plots and estimated seedling survival based on greenhouse results of 5 grass species for 2,3 , and 5 wet days followed by 5 dry days. Greenhouse data normalized by the corresponding field water sequence germination rates.

Asay, K.H., and D.A. Johnson. 1987. Breeding for improved seedling establishment in cool-season grasses. p. 173-176. In: Proc. Symposium "Seed and Seedbed Ecology of Rangeland Plants," Tucson, Ariz., 21-23 April 1987. USDA, Agr. Res. Serv. Washington, D.C.

Assoc. Off. Seed Anal. 1970. Rules for testing seeds. Proc. Assoc. Off. Seed Anal. 60:1-116.

Collis-George, N., and J.B. Hector. 1966. Germination of seeds as influenced by matric potential and by area of contact between seed and soil water. Aust. J. Soil Res. 4:145-164.

Cox, J.R., and G.L. Jordan. 1983. Density and production of seeded range grasses in southeastern Arizona (1970-1982). J. Range Manage. 36:649-652.

Frasier, G.W. 1985. A precision planter for seedling emergence evaluation. J. Range Manage. 38:187-190.

Frasier, G.W. 1986. Water requirements for range plant establishment. p. 839-846. In: Proc. ASCE Water Forum '86 Conference, Amer. Soc. Civil Engin., Long Beach, Calif.

Frasier, G.W., J.R. Cox, and D.A. Woolhiser. 1985. Emergence and survival response of seven grasses for six wet-dry sequences. J. Range Manage. 38:372-377.

Frasier, G.W., D.A. Woolhiser, and J.R. Cox. 1984. Emergence and seedling survival of two warm-season grasses as influenced by the timing of precipitation: A greenhouse study. J. Range Manage. 37:7-11.

Sosebee, R.E., and C.H. Herbel. 1969. Effects of high temperatures on emergence and initial growth of range plants. Agron. J. 61:621-624. 